\title{
Por uma história comparada do esporte: possibilidades, potencialidades e limites
}

Victor Andrade de Melo*

\begin{abstract}
Resumo: Depois de muitos anos em que a produção brasileira esteve limitada a poucas referências, a partir da década de 1990 é possível observar um aumento exponencial do número de estudos históricos que têm como objetos de investigação as práticas corporais institucionalizadas, entre as quais o esporte. Uma característica marcante observada nessa produção é que normalmente trata-se de estudos locais ou regionais. Este artigo objetiva refletir sobre as possibilidades, potencialidades e limites do método da História Comparada para ampliar as contribuições dos estudos históricos relacionados ao esporte. Espera-se que possa contribuir para problematizar o atual estágio de nossa produção historiográfica, apresentando alternativas que podem dar continuidade ao processo de qualificação de nossas investigações, e mesmo ampliar o diálogo com a comunidade científica internacional.
\end{abstract}

Palavras-chave: Esporte. História. Historiografia.

\section{INTRODUÇÃO}

O processo do método comparativo é justamente o que permite estabelecer o estranhamento, a diversificação, a pluralização e a singularidade daquilo que parecia empiricamente diferente ou semelhante, posto pelo habitus e reproduzido pelo senso comum. (THEML; BUSTAMANTE, 2003, p. 22).

A mudança cultural na história do esporte [...] fez crescer uma série de novas questões ontológicas e

\footnotetext{
- Professor do Programa de Pós-Graduação em História Comparada/IFCS e da Escola de Educação Física e Desportos. Universidade Federal do Rio de Janeiro (UFRJ). Coordenador do Grupo de Pesquisa Anima: Lazer, Animação Cultural e Estudos Culturais e do Grupo de Pesquisa Espaço Virtual de História do Esporte. Pesquisador do Laboratório de Estudos do Tempo Presente/IFCS/UFRJ, Brasil. Bolsista de produtividade de pesquisa/CNPq. E-mail: victor.a.melo@uol.com.br
} 
epistemológicas, particularmente relacionadas com a verdade, o conhecimento e suas relações com o poder. Mas historiadores do esporte não devem permitir que essas questões dominem completamente a agenda de discussão; nem devem continuar ignorando metodologias empíricas mais tradicionais. (BOOTH, 2000, p. 20).

O surgimento de uma "subdisciplina" denominada "História do Esporte" deve ser certamente entendido a partir da emergência da Nova História Cultural, que, a despeito de raízes, ocorrências e influências anteriores, melhor se sistematiza nos anos 1970, conforme nos informa Peter Burke (2005). A partir dos diálogos estabelecidos com a Antropologia, no âmbito de valorização da cultura como objeto de estudo nas Ciências Humanas e Sociais, as diversas "práticas" ganham relevância e passam a ser motivo de investigação histórica:

"Práticas" é um dos paradigmas da Nova História Cultural: a história das práticas religiosas e não da teologia, a história da fala e não da lingüística, a história do experimento e não da teoria científica. Graças a essa virada em direção às práticas, a história do esporte, que antes era tema de amadores, tornou-se profissionalizada, um campo com suas próprias revistas, como o International Journal of History of Sport. (BURKE, 2005, p. 78).

Essa organização recente traz uma série de problemas conceituais que precisam ser encarados. Podemos mesmo chamar a "História do Esporte" de uma subdisciplina (que expressaria a idéia de algo já consolidado ou em vias de consolidação) ou trata-se de, dialogando com as idéias de José de Assunção Barros (2004, p.186), um dos muitos domínios da História, que "[...] surgem e desaparecem com rapidez, às vezes perseguindo ditames da moda e caindo para segundo plano tão logo se saturam"

De qualquer maneira, para demonstrar que há uma forte tendência de consolidação, não é possível deixar de reconhecer o surgimento de sociedades nacionais (como a North American Society of Sport History, entre outras) e internacionais (como a

Movimento, Porto Alegre, v. 13, n. 03, p. 11-41, setembro/dezembro de 2007. 
International Society for the History of Physical Education and Sport); de periódicos (como a já citado Internation Journal, o Sport History Review e o Journal of Sport History, entre outros); de eventos científicos (como o Congresso Internacional do Comitê Europeu de História do Esporte, já na sua $12^{a}$ edição) e de departamentos específicos em universidades européias e norteamericanas.

As imprecisões conceituais chegam também à própria definição desse "movimento": História do Esporte, História da Educação Física e do Esporte ou História das Atividades Físicas? Quando falamos em História do Esporte, está contemplada a história da ginástica? E o que falar da história da dança, que também tem vinculação com a História da Arte? Particularmente, sem intenção de resolver definitivamente o problema, tenho trabalhado com a idéia de "História das Práticas Corporais Institucionalizadas", algo que abarcaria em um mesmo campo de investigação (sem excluir outras possibilidades de diálogos) fenômenos como o esporte, a capoeira, a ginástica, as relativamente recentes práticas físicas "alternativas" (antiginástica, eutonia, etc.), a Educação Física (entendida enquanto uma disciplina escolar e uma área de conhecimento também relativamente autônoma), as práticas chamadas de "pré-esportivas", entre outras.

Independente dessas polêmicas e discussões conceituais, parece claro que a "História do Esporte" nas últimas décadas emerge enquanto um novo campo profissional de investigação histórica, se não somente conduzido por "historiadores de formação", certamente por pesquisadores que, independente de sua filiação acadêmica original, procuram fazer uso das discussões metodológicas do campo da História.

O Brasil não ficou alheio a esse processo. Depois de muitos anos, nos quais a produção brasileira esteve limitada a poucas referências, a partir da década de 1990 é possível observar um aumento exponencial do número de estudos históricos que têm como objetos de investigação as práticas corporais institucionalizadas (MELO, 1999). Como fatores que estiveram articulados com o 
crescimento quantitativo de artigos, livros e trabalhos de pós-graduação podem-se identificar:

a) a abertura de espaços constantes para a discussão em eventos científicos. Na área de Educação Física, podemos observar tal ocorrência, no Congresso Brasileiro de Ciências do Esporte (que dedica ao tema um grupo de trabalho) e com a freqüente realização do Congresso Nacional de História do Esporte, Lazer e Educação Física (cuja $10^{\mathrm{a}}$ edição foi realizada no ano de 2006, na Universidade Federal do Paraná); na área de História, destaca-se a realização de Simpósios Temáticos específicos nos congressos nacionais e estaduais da Associação Nacional de História (ANPUH);

b) o incentivo à publicação em periódicos nacionais. $\mathrm{O}$ assunto foi, por exemplo, a temática central de três edições da Revista Brasileira de Ciências do Esporte ${ }^{1}$ e de um número do periódico Estudos Históricos $;^{2}$

c) o reconhecimento da importância do assunto por pesquisadores de várias áreas de conhecimento, além de Educação Física e História: Sociologia, Antropologia, Ciências da Comunicação, Direito, entre outras. Foram, inclusive, abertos espaços privilegiados nas atividades de algumas entidades científicas, caso da Associação Brasileira de Antropologia (ABA), da Associação Nacional de Pós-Graduação em Ciências Sociais (ANPOCS) e da Sociedade Brasileira de Estudos Interdisciplinares da Comunicação (INTERCOM). Vale ainda destacar a posição da ANPUH, que recentemente solicitou ao Conselho Nacional de Pesquisa (CNPq) a inclusão da especialidade História do Esporte na nova tabela de área de conhecimentos da entidade;

d) o aumento do número de grupos de pesquisa; uma busca no diretório CNPq permitiu encontrar cerca de 30 grupos que de alguma forma estão envolvidos com a temática.

${ }^{1}$ Colégio Brasileiro de Ciências do Esporte, v. 25, n. 1 (set. 2003); n. 2 (jan. 2004), n. 3 (maio 2004).

${ }^{2}$ Centro de Pesquisa e Documentação de História Contemporânea (CPDOC) da Fundação Getúlio Vargas, n. 23, 1999.

Movimento, Porto Alegre, v. 13, n. 03, p. 11-41, setembro/dezembro de 2007. 
Nesse contexto, vale a pena ainda destacar: a) o crescimento do número de livros de informações para público não-acadêmico, majoritariamente escritos por jornalistas e lançados normalmente por ocasião de efemérides ou para homenagear determinado ídolo esportivo; b) no âmbito acadêmico, a preocupação com o aperfeiçoamento metodológico das investigações, a partir de um diálogo mais constante com o arcabouço teórico das ciências humanas e sociais.

Uma característica marcante observada nessa produção recente é que normalmente tratam-se de estudos locais ou regionais, relacionados a cidades ou estados, clubes, personalidades, fatos ou temas específicos. Obviamente isso se dá por ser uma clara tendência nas investigações históricas como um todo, algo acirrado pelas próprias condições operacionais que se impõe hodiernamente aos pesquisadores, notadamente a escassez de tempo (especialmente as pressões a que estão submetidos os programas de mestrado e doutorado) e a dificuldade de acesso a arquivos e documentos. De qualquer forma, esse conjunto de pesquisas nos permite vislumbrar um panorama nacional dos diversos arranjos dos fenômenos culturais Esporte, Educação Física, Ginástica, Dança, Capoeira, etc.

A despeito da importância dessa produção, algumas questões merecem ser levantadas: não estaríamos perdendo a visão do "todo" em função da fragmentação das abordagens? Como ampliar nossa visão acerca da realidade nacional sem crer que essa é simplesmente o resultado da soma dos entendimentos locais? Como construir hipóteses mais amplas, pensando, por exemplo, no cenário latinoamericano, contexto no qual estamos inseridos não somente por questões geográficas, mas também por relações históricas, culturais e políticas? Como fazer dialogar a produção brasileira com o que tem sido produzido internacionalmente? Talvez o método da História Comparada possa nos apontar alguns indicadores para responder, ainda que parcialmente, tais perguntas, como nos indica introdutoriamente as palavras de Marc Bloch:

A História Comparada, tornada mais fácil de se conhecer e de se utilizar, animará com seu espírito

Movimento, Porto Alegre, v. 13, n. 03, p. 11-41, setembro/dezembro de 2007. 
os estudos locais, sem os quais ela nada pode, mas que, sem ela, a nada chegariam. Numa palavra, deixemos, por favor, de falar eternamente de história nacional para história nacional, sem nos compreendermos. (BLOCH apud HAUPT, 1998, p. 213).

Nessa mesma direção, Kocka (2003, p. 41)é ainda mais explícito:

Freqüentemente, historiadores se concentram na história de seu país ou região. Por causa disso, a comparação pode ter um efeito desprovincializante, liberador, abrindo perspectivas, com conseqüências para a atmosfera e estilo da profissão. Esta é uma contribuição da comparação que não deveria ser subestimada.

Certamente não desconhecemos que as experiências de uso do método da História Comparada podem e tem sido também utilizadas para realização de estudos locais, como nos lembra Barros (2007, p. 17): "Comparar macro-realidades ou comparar micro-realidades é legítimo em cada caso: e entre estas operações guardar-se-á o mesmo tipo de distinção que emerge da escolha entre comparar estrelas e comparar átomos". Sem negar isso, apenas levantamos a possibilidade de, inclusive no caminho aberto pelos teóricos que pioneiramente defenderam o método comparativo, ampliar o olhar histórico para cenários mais amplos.

Considerando as possibilidades do método comparativo, desde o ano de 2002 está em funcionamento, no Instituto de Filosofia e Ciências Sociais da Universidade Federal do Rio de Janeiro, o Programa de Pós-Graduação em História Comparada (PPGHC), ${ }^{3}$ organizado em três linhas de pesquisa: História Comparada das Diferenças Sociais, História Comparada das Instituições e Formas Políticas e História Comparada das Formas Narrativas. No interior dessa última linha, tendo em vista a construção de um conjunto de reflexões a partir das contribuições do método comparativo,

${ }^{3}$ Credenciado pela Capes em 21 de maio de 2004. Maiores informações podem ser obtidas em www.ifcs.ufrj.br.

Movimento, Porto Alegre, v. 13, n. 03, p. 11-41, setembro/dezembro de 2007. 
constituímos uma área de investigação denominada "História das práticas corporais e de lazer". ${ }^{4}$

Dialogando com as experiências de pesquisa em desenvolvimento nesse âmbito e com a literatura nacional e internacional, este artigo objetiva refletir sobre as possibilidades, potencialidades e limites do método da História Comparada para ampliar as contribuições dos estudos históricos ligados ao esporte e às práticas corporais institucionalizadas como um todo.

Vale destacar que em nosso país não é possível identificar muitas iniciativas de utilização do referido método nas investigações históricas relacionadas a tais objetos. Mesmo quando se observa alguma perspectiva de comparação, esta normalmente não procura dialogar com as reflexões dos autores que se debruçam sobre tal possibilidade. Assim, o que nos coloca Barros (2007, p. 3) parece ser bastante estimulante:

Ao impor àqueles que a praticam um novo modo de pensar a história a partir da construção de seu recorte, e um modo bastante específico de trabalhar sobre as fontes e realidades históricas assim observadas - a História Comparada revela-se oportunidade singular para que se repense a própria história em seus desafios e em seus limites. Talvez seja isto, mais do que tudo, o que tem contribuído para fazer da História Comparada matéria privilegiada para um intenso debate entre os historiadores nos seus encontros profissionais, mesmo que ainda não exista uma quantidade tão considerável de trabalhos relacionados mais diretamente a esta modalidade.

$\mathrm{Na}$ expectativa de que esse método possa trazer colaborações para os historiadores do esporte e certo de que não podemos nos privar de travar tal debate, espero que este artigo possa contribuir para problematizar o atual estágio de nossa produção, apresentando

\footnotetext{
${ }^{4}$ Ligadas à área de investigação, temos ainda oferecido disciplinas de mestrado (notadamente "Esporte: conceitos e discursos" e "Lazer: conceitos e discursos") e estão em desenvolvimento seis dissertações de mestrado, cinco sob minha orientação e uma sob orientação do Prof. Dr. Francisco Carlos Teixeira da Silva.
}

Movimento, Porto Alegre, v. 13, n. 03, p. 11-41, setembro/dezembro de 2007. 
alternativas que podem dar continuidade ao processo de qualificação de nossas investigações, bem como mesmo ampliar o nosso diálogo com a comunidade científica internacional, inclusive e fundamentalmente com os colegas da América Latina.

\title{
2 A HISTÓRIA COMPARADA: POSSIBILIDADES, POTENCIALIDADES E LIMITES DE CONTRIBUIÇÃO PARA A HISTÓRIA DO ESPORTE
}

\begin{abstract}
A História Comparada, no nosso entender, subentende mais do que uma justaposição ou uma divisão, seja em termos do tipo de História, seja em termos dos períodos históricos. A História Comparada é o método de pesquisa que convida a uma mudança de atitude no molde de fazer História; é uma nova perspectiva dos pesquisadores como sujeitos em relação ao objeto de pesquisa. (THEML; BUSTAMANTE, 2003, p. 22).

Historiadores do esporte geralmente usam o método comparativo como simples recurso de alusão a aspectos luminares de casos particulares. Assim, reduzem o poder da comparação sistemática. Esse olhar reduzido tem indubitavelmente reduzido a credibilidade intelectual da história do esporte a sua contribuição para a história social mais ampla. (BOOTH, 2000, p. 20).
\end{abstract}

No período pós-Segunda Grande Guerra, duas ocorrências políticas influenciaram decisivamente no crescimento do número de estudos históricos comparados: os movimentos de descolonização dos países africanos e asiáticos e a emergência de novas potências internacionais fora do continente europeu (Estados Unidos e União Soviética em um primeiro momento, e Japão posteriormente; Índia e China mais recentemente). Isso desencadeou reflexões sobre um certo provincianismo e etnocentrismo na "maneira européia" de fazer história.

Certamente outras marcas do período pós-guerra contribuíram para a ampliação da perspectiva histórica e para o crescimento do

Movimento, Porto Alegre, v. 13, n. 03, p. 11-41, setembro/dezembro de 2007. 
método comparativo, entre as quais: as preocupações com o ultranacionalismo; a emergência das inquietações com os países em desenvolvimento; a ascensão da cultura como um dos elementos centrais para se pensar a dinâmica social; e mesmo os movimentos de globalização, que trouxeram à tona um sem número de arranjos sociais específicos pouco conhecidos. Como bem chama a atenção Kocka (2003, p. 42):

Há, afortunadamente, muito interesse agora nas abordagens transnacionais para a História. As diferentes correntes de História Global ou História Mundial são um exemplo disso. Abordagens comparativas, comparações internacionais e interculturais, são apenas uma forma de perceber o crescente compromisso transnacional. Há outras formas, por exemplo, de estudos e interpretações usando teorias pós-coloniais.

Nesse ponto específico, vale a pena falar dos desafios que se colocam para o historiador do esporte. É importante lembrar que estamos lidando com uma das manifestações culturais contemporâneas mais influentes e presentes em países diferentes. É provável que seja uma das práticas sociais mais fortes no que se refere à transnacionalidade, onde se destacam seus eventos mais conhecidos (os Jogos Olímpicos e a Copa do Mundo de Futebol) e duas de suas entidades organizativas (a Federação Internacional de Futebol e o Comitê Olímpico Internacional, ambas com mais membros que a Organização das Nações Unidas). Assim sendo, desde o início parece que uma abordagem histórica transnacional pode se apresentar como fértil perspectiva para as investigações relacionadas ao objeto. ${ }^{5}$

No contexto antes descrito, não por acaso a perspectiva da História Comparada esteve já contemplada entre as proposições de alguns dos membros da Escola dos Annales, ${ }^{6}$ notadamente nas

\footnotetext{
${ }^{5}$ Uma experiência recente e interessante nesse sentido foi desenvolvida por Franklin Foer (2005). Ressalvamos, contudo, que a forma adotada pelo autor não aproxima o livro da perspectiva da História Comparada, sendo antes um panorama multifacetado.

${ }_{6}^{6}$ Maiores informações sobre a Escola dos Annales podem ser obtidas no estudo de Burke (1992).

Movimento, Porto Alegre, v. 13, n. 03, p. 11-41, setembro/dezembro de 2007.
} 
reflexões e investigações de Marc Bloch, ainda que fosse motivo de desconfiança por parte de Lucien Febvre. ${ }^{7}$

As origens do método comparativo, contudo, não se encontram stricto sensu na disciplina História. Durkheim, um dos autores seminais da Sociologia, já lançara antes a proposição, afirmando que para qualquer teoria social a comparação não é um ramo específico, mas a teoria em si, pois só ela permitiria passar da descrição para a análise de fatores, algo que também esteve de alguma forma constantemente presente nas reflexões de Max Weber (BURKE, 2002). A comparação é também uma das marcas de um autor que, embora filiado intelectualmente à Sociologia, trouxe grandes contribuições para os estudos históricos, inclusive para as compreensões sobre a prática esportiva: Norbert Elias. ${ }^{8}$

Voltando à História, é inegável a contribuição de Marc Bloch para o método comparativo. Para o autor, seria uma possibilidade de entender especificidades e generalidades de cada um dos fenômenos estudados, o que também permitira maior profundidade na discussão das causas e origens. Bloch foi um seguidor de Durkeim, se afastando das idéias de comparação de Weber: ao contrário deste não estava interessado em captar "as ausências", mas sim as regularidades, as "semelhanças".

Poder-se-ia, para Bloch, adotar a comparação entre sociedades próximas (sua preferência e indicação principal) e entre sociedades distantes no tempo e no espaço (BURKE, 2002). De fato, persistiam preocupações quanto aos limites do método: ${ }^{9}$

\footnotetext{
Havia o receio de que a História Comparada pudesse resultar em uma abstração excessiva pautada em uma postura de que tudo era passível de comparação independentemente de tempo/ espaço, negando justamente o que era caro aos
}

\footnotetext{
${ }^{7}$ Maiores informações podem ser obtidas no artigo de Haupt (1998).

${ }^{8}$ Elias é hoje, no Brasil, um dos autores mais utilizados nos estudos históricos e sociológicos sobre o esporte. Isso, contudo, não significa que o método comparativo seja de corrente utilização entre nós.

${ }^{9}$ Uma compreensão mais aprofundada sobre o percurso da História Comparada pode ser obtida nos estudos de Haupt (1998) e de Hannick (2001).
}

Movimento, Porto Alegre, v. 13, n. 03, p. 11-41, setembro/dezembro de 2007. 
historiadores: privilegiar a singularidade, localizando as especificidades e diferenças, e indagar acerca dos fatores/elementos que as determinaram visando compreender a dinâmica, o comportamento, as imbricações entre os diferentes aspectos que moldam uma dada realidade sob observação. (THEML; BUSTAMANTE, 2003, p. 27).

É importante perceber que a despeito do reconhecimento de algumas de suas contribuições, muitas polêmicas e desafios ainda permanecem para os que se interessam por esse método. Se a idéia de comparar parece ser inerente a qualquer pesquisa histórica, como defende Kula (1974), o que vai diferenciar o uso do método da História Comparada? Barros (2007) propõe que devemos ultrapassar uma abordagem mais intuitiva e cotidiana por uma observação mais profunda e sistematizada. Ressalta claramente que o comparativismo histórico e a História Comparada não são a mesma coisa, ainda que se identifique uma clara afinidade entre ambos:

[...] uma vez que os procedimentos comparativos são tão fundamentais e viscerais para a história, cedo ou tarde, na história da historiografia, haveria de surgir uma modalidade como a História Comparada, que faz da analogia, do contraste, da ultrapassagem do recorte espaço-temporal tradicionalmente unicentrado, o campo eleito de suas abordagens. (BARROS, 2007, p.14).

Um dos grandes desafios diz respeito a uma pergunta central: afinal, o que é comparar numa abordagem histórica? Em linhas gerais seria fácil definir: tratar-se-ia de investigar dois ou mais fenômenos em perspectiva, buscando semelhanças e diferenças entre o que é comparado.

No âmbito internacional, na área de História do Esporte, essa idéia tem sido a mais constantemente utilizada, ainda que a História Comparada também por lá ainda não seja de uso corrente, como demonstra o estudo de Douglas Booth (2000) ao comentar as experiências de autores como Kevin MacAleer (em investigação sobre a relação entre a construção da masculinidade, os duelos armados na Alemanha e as disputas de boxe na Inglaterra), de

Movimento, Porto Alegre, v. 13, n. 03, p. 11-41, setembro/dezembro de 2007. 
Andrew Moore (que comparou as origens das ligas de rugby australianas e britânicas) e de John Hoberman (ao contrastar o Movimento Olímpico com o Movimento Escoteiro, a Cruz Vermelha e as tentativas de difusão do esperanto). Todos os três, aliás, fazem questão de apresentar o método comparativo como possibilidade de ampliar as pesquisas históricas ligadas ao esporte, identificando a sua pouca utilização.

Na verdade, como veremos, tal método não é tão simples quanto a princípio pode parecer. Temos que considerar que tal perspectiva de pesquisa traz um grande número de peculiaridades que não podem ser desprezadas. E mais ainda, que recentemente novas reflexões acerca da História Comparada, notadamente as impulsionadas por Marcel Dettiene (2004), tornam ainda mais complexas, mesmo que muito interessantes, os esforços de historiadores que com tal possibilidade se envolvem.

Que vantagens poderia nos trazer o método comparativo? Para Jurgen Kocka (2003), os propósitos da História Comparada podem ser apresentados como: heurísticos - permite identificar novas questões e novos problemas que não teriam sido notados em uma primeira abordagem; descritivos - possibilita aprofundar o esclarecimento sobre casos singulares à medida que estes são contrastados com outros; analíticos - já que permite o levantamento e a resposta de questões causais; paradigmático - pois induz a uma desreferencialização do historiador, ao afastá-lo daquele ponto de observação que mais domina.

Exemplifiquemos: é certo que estudar a história do esporte desde o caso do Rio de Janeiro pode ajudar a melhor compreender a dimensão do fenômeno esportivo em terras brasileiras, assim como entender de forma mais ampla a nossa sociedade. É certo que o caso daquela cidade guarda muito da realidade nacional. Mas se o compararmos a outras cidades, não seria possível ampliar nossa visão sobre a complexidade do problema? No contraste com as peculiaridades de São Paulo, não poderiam surgir novas questões por nós não percebidas quando olhamos detidamente a capital carioca? Nesse sentido, não nos traria de volta ao próprio Rio de

Movimento, Porto Alegre, v. 13, n. 03, p. 11-41, setembro/dezembro de 2007. 
Janeiro para melhor o entendermos? Essa comparação poderia provavelmente nos permitir contestar certas assertivas e não só apresentar novas conclusões, como também desencadear diferentes problemas de investigação, construir novas hipóteses.

Ciro Flamarion Cardoso e Hector Brignoli (1983), aliás, apontam que o método comparativo contribui para com o melhor controle sobre as hipóteses e generalizações, para superar a herança historiográfica construída a partir da reificação das fronteiras políticas, para melhor distinção das singularidades irredutíveis dos fenômenos estudados. Para eles, ainda que não perfeita, é a única alternativa que tem a história para lidar com a "impossibilidade de aplicar o método experimental" (CARDOSO; BRIGNOLI, 1983, p. 411).

Por certo, ao redor das discussões sobre o método comparativo se encontram os debates sobre a própria cientificidade da disciplina História. Não quero aprofundar tal questão, por não a considerar central para este estudo, mas vale a pena ter em conta o alerta de Cardoso e Brignoli (1983, p. 410):

A polêmica entre os defensores e os detratores da comparação na História pode ser tida como a manifestação, no campo da disciplina, da oposição entre duas atitudes científicas, ambas possivelmente necessárias: por um lado a busca da precisão, do exato, do certo, o que leva a destacar o caráter individual e único de cada objeto observado; por outro lado, a "corrida criadora para as verdadeiras descobertas", que exige apelo à comparação e à abstração. De qualquer modo, como Witold Kula o demonstra, nenhum trabalho científico, por mais limitado e monográfico que seja, pode dispensar totalmente o método comparativo, pois é impossível a introdução de novos elementos em um terreno qualquer do conhecimento sem compará-los com os já conhecidos; esta comparação, embora ás vezes não explícita, é absolutamente necessária, pois de outro modo não se poderia dar um nome aos mencionados fenômenos novos.

Outra contribuição que o método comparativo pode trazer para os estudos históricos, algo que nos interessa notavelmente, dada

Movimento, Porto Alegre, v. 13, n. 03, p. 11-41, setembro/dezembro de 2007. 
a natureza de nossos objetos de estudo, é a necessidade de o historiador assumir uma profunda e convicta postura interdisciplinar, buscando nas ciências humanas e sociais como um todo o arcabouço metodológico e teórico que pode ampliar o seu olhar. ${ }^{10}$

No cenário internacional, para Booth (2000) esse pode ser considerado como um dos motivos que afasta os historiadores do método comparado, já que esses têm se mostrado pouco dispostos a diálogos com as reflexões advindas de outras áreas do conhecimento. $\mathrm{O}$ autor chega a considerar que, nesse sentido, são mais notáveis os esforços dos que se envolvem com a Sociologia do esporte. ${ }^{11}$

Na experiência de nosso grupo de investigação, Cléber Augusto Dias (2006) está assumindo tal desafio e investigando a recente organização dos esportes de natureza no contexto de reformas urbanas da cidade do Rio de Janeiro nas décadas de 1960 e 1970, considerando inclusive os planos urbanísticos propostos (como o Plano Lúcio Costa, para a Barra da Tijuca). Fazendo uso de arcabouço teórico da Arquitetura e do Urbanismo, bem como da Geografia, o pesquisador discute as relações entre esporte e cidade, comparando inclusive a organização de surfe e montanhismo nesse cenário, dialogando com a idéia de "mercado de consumo" gerado ao redor das práticas corporais.

E quais seriam os riscos e desafios da História Comparada? Para Kocka (2003), o método comparativo cria tensão com alguns aspectos usuais das pesquisas históricas tradicionais: com a questão da sucessão cronológica de fatos, já que se trata fundamentalmente de discutir um problema; com o uso de fontes, já que o historiador passa a ter que buscá-las para além de sua localidade; com a idéia

\footnotetext{
${ }^{10}$ Não por acaso, alguns autores até mesmo têm questionado a divisão tradicional disciplinar utilizada para o estudo acadêmico da prática esportiva, propondo que deveríamos implementar uma área interdisciplinar denominada Estudos do Esporte, já não mais encaminhada no mesmo sentido que o tradicional uso das Ciências do Esporte. O diálogo com os estudos culturais, a idéia de processualidade e a busca dos diálogos entre disciplinas parece uma perspectiva alvissareira.

${ }^{11}$ Isso é notável, por exemplo, nos estudos de Richard Giulianotti $(2004,2005)$.
}

Movimento, Porto Alegre, v. 13, n. 03, p. 11-41, setembro/dezembro de 2007. 
de contexto, já que o esforço do pesquisador tem que se dar a partir da compreensão de mais de uma realidade.

No âmbito de nossas investigações vivenciamos concretamente alguns desses limites. No que se refere à questão das fontes e do contexto, André Schettino (2006) busca documentos e compreensões sobre o ciclismo e a bicicleta na Paris da transição do século XIX para o XX. Já Maurício Drumond (2006) e Ricardo Pinto Santos (2006) se dedicam a estudar o futebol na Argentina, tarefa um pouco mais simples, embora não menos árdua, em função da proximidade geográfica desse país, o que permite a realização de viagens para trabalhos nos arquivos e bibliotecas. Álvaro do Cabo se depara com outro fator dificultador, já que estuda as Copas do Mundo realizadas entre Brasil, Argentina e Uruguai, dois outros países a investigar. Aqui se coloca ainda a questão do domínio lingüístico, mais complexo no caso de Schettino, que tem se dedicado ao estudo do francês para dar conta de sua pesquisa. Conduzindo nossas ações há o intuito de não somente fazer uso de fontes secundárias, mas também de dialogar com as primárias, disponíveis em outros países.

No caso desses estudos, há também que se ter em conta as peculiaridades locais na definição das categorias a serem analisadas. Por exemplo, quando Maurício Drumond (2006) trabalha a comparação dos discursos sobre o futebol nos governos nacionais-estatistas de Vargas (Brasil) e Perón (Argentina), procura ter em conta que suas organizações carregam diferenças significativas (como também, por certo, possíveis semelhanças). Da mesma forma, quando Ricardo Pinto (2006) discute a questão do envolvimento das minorias sociais nos primórdios do futebol em ambos os países, considera as peculiaridades de formação do discurso acerca da construção da identidade nacional, onde se destaca a figura do mulato na realidade brasileira e do criollo na Argentina.

Nesse sentido, vale ter em vista os alertas de Burke (2002) e de Cardoso e Brignoli (1983), que sugerem que evitemos algumas armadilhas: não estabelecer uma das sociedades analisadas como "padrão", o que levaria o historiador a incorrer no equívoco do etnocentrismo; evitar os anacronismos, o que não significa abandonar

Movimento, Porto Alegre, v. 13, n. 03, p. 11-41, setembro/dezembro de 2007. 
a visão analítica e crítica do pesquisador, mas sim não estabelecer um conceito de uma época como padrão para julgar outro período histórico; ter cuidado com as especificidades das sociedades estudadas, evitando ao máximo confundir semelhanças superficiais com analogias profundas, bem como só identificando diferenças sem que isso possa servir para aprofundar os olhares sobre o estudado.

Por exemplo, se estamos supostamente desenvolvendo um estudo comparado sobre a presença das mulheres no esporte brasileiro e no uruguaio, qual dos dois seria o padrão de análise? Nenhum dos dois, pois devemos entender a especificidade de cada caso no que se refere ao problema a ser estudado. Nesse sentido, devemos compreender, em cada um desses países, quais foram as peculiaridades das lutas e conquistas femininas, do desenvolvimento do esporte e das relações entre mulheres e esporte, tendo em vista as dimensões postas nos períodos históricos analisados. Somente a partir daí será possível buscar diferenças e semelhanças, sempre com o cuidado de verificar o grau dessas e a suas contribuições para iluminar a questão que nos conduz a investigação.

Douglas Booth (2000), ao tematizar especificamente a história do esporte, chama ainda a atenção para termos cuidado com a adoção de uma estrutura a priori como modelo, desconsiderando as peculiaridades e ressignificações locais. Lembra o autor que os atores são ativos e que entender as relações entre o geral e o particular constitui-se em exercício fundamental no método comparativo.

Há, na verdade, uma importante questão a ser respondida pelo pesquisador que se envereda por essa possibilidade de estudo: o que comparar? Se o historiador não decidir e avaliar bem as condições concretas das quais dispõe (isso inclui entre outras coisas um arcabouço conceitual, o acesso a fontes, a compreensão do contexto), corre o risco de somente transitar pela superficialidade ou traçar afirmações por demais genéricas. Independente do posicionamento teórico acerca dos tipos possíveis de comparação, é preciso conhecer bem o que se pretende comparar e não se pode confundir comparação com justaposição, já que não se trata de simplesmente colocar lado a lado descrições individuais.

Movimento, Porto Alegre, v. 13, n. 03, p. 11-41, setembro/dezembro de 2007. 
Vamos dar um exemplo concreto ligado a nossa área de estudo. Em 2003, o pesquisador argentino Pablo Alabarces lançou o belo livro Futbologías: fútbol, identidad y violencia en America Latina. Aí podemos encontrar artigos sobre peculiaridades do velho esporte bretão na Argentina, Equador, Colômbia, Brasil, Uruguai, Chile. A despeito da importância da iniciativa, não podemos considerá-la como exemplo de um estudo comparativo, pois, ainda que traga bons insights para pensar a América do Sul, se trata basicamente da justaposição de vários olhares específicos, e não de busca de semelhanças e diferenças de forma sistemática em uma mesma investigação.

É considerando tais alertas que Maurício Drumond (2006) e Ricardo Pinto (2006) investigam o futebol brasileiro e o argentino. O primeiro busca discutir o "uso político do esporte" no contexto dos governos de Vargas e Peron, enquanto o segundo debruça-se sobre a apreensão do esporte pelas camadas populares de ambos os países na transição dos séculos XIX e XX. Privilegiando fundamentalmente os discursos da imprensa, ambos desejam captar as tensões que percorreram a construção de representações ao redor do futebol na América Latina, a partir da comparação sistemática de dois países onde o futebol é muito importante.

Há ainda algumas diferentes apreensões que precisam ser consideradas. Alguns autores afirmam que só é possível "comparar o comparável" (entre eles os já citados CARDOSO E BRIGNOLI, 1983), se alinhando às preocupações de Bloch; certamente uma posição mais tímida e circunscrita de comparação. Para estes, se fossem comparadas sociedades distantes no tempo e no espaço, ao menos se devia garantir estruturas e conjunturas semelhantes.

Obviamente que não estamos a dizer que, ainda que tímida, essa não é uma possibilidade concreta de encaminhar os esforços comparatórios. Em nossas experiências, por exemplo, André Schetino (2006) trabalha nessa direção, ao desenvolver uma análise comparada sobre a presença e a importância da bicicleta nas cidades de Paris e Rio de Janeiro na transição do século XIX para o XX.

Movimento, Porto Alegre, v. 13, n. 03, p. 11-41, setembro/dezembro de 2007. 
Considerando tal artefato como um dos símbolos da modernidade (WEBER, 1988), pretende discutir as diferenças e semelhanças nas considerações acerca da introdução desse objeto da cultura material no cotidiano das duas cidades. Dedicado a discutir as relações entre esporte e modernidade, o pesquisador debruça-se ainda sobre o desenvolvimento do ciclismo, bem como faz uso de obras de arte para guiar sua interpretação (a bicicleta foi bastante representada nas artes plásticas, notadamente no movimento futurista, e no cinema).

Já outros autores, como Marcel Detienne (2004), ampliam essa possibilidade de entender o método, propondo que é sim possível "comparar o incomparável", ou seja, fatos que não são necessariamente contemporâneos ou de uma localidade geograficamente próxima. Como cremos que as sociedades são bastante complexas:

$$
\begin{aligned}
& \text { É necessário afastar-se de todo tipo de } \\
& \text { hieraquização de culturas e sociedades, de níveis } \\
& \text { de realidades estanques ou de supremacia de um } \\
& \text { domínio sobre o outro, pois existem diversas redes } \\
& \text { de imbricações, quando se tratam dos fenômenos } \\
& \text { sociais, que não são necessariamente lineares, } \\
& \text { causais e evolutivas. Estas redes têm mais } \\
& \text { condições de serem percebidas e elucidadas quando } \\
& \text { se tornam objeto de uma abordagem comparativa } \\
& \text { pela construção de um conjunto de problemas [...]. } \\
& \text { Logo, não há preocupação com hierarquias pois } \\
& \text { não se objetiva formular modelos abstratos, leis } \\
& \text { gerais, relações de causalidade, origem nem } \\
& \text { essência dos fenômenos, mas sim descobrir formas } \\
& \text { moventes e múltiplas com as quais as sociedades } \\
& \text { de depararam, as representaram e se transformaram. } \\
& \text { (THEML; BUSTAMANTE, 2004, p. 10). }
\end{aligned}
$$

Nesse caso, é bom considerar a proposta de Paul Veyne (1989): a de estabelecimento de invariantes ou constantes trans-históricas, algo que permitiria que não se perdesse a visão da individualidade do fenômeno e ainda assim se ampliasse o seu olhar sobre ele:

[...] a conceitualização de um invariante permite explicar os acontecimentos; atuando sobre as

Movimento, Porto Alegre, v. 13, n. 03, p. 11-41, setembro/dezembro de 2007. 
variáveis, podemos recriar, a partir do invariante, a diversidade das modificações históricas; desta forma explicitamos o não pensado e esclarecemos o que estava apenas vagamente concebido ou apenas pressentido. (VEYNE, 1989, p. 13).

A questão instigante que nos lança o autor é que o que organiza os fatos históricos são noções e não períodos: "Esqueçamos de uma vez para sempre os períodos, as civilizações, as histórias nacionais, ou antes não lhes sacrifiquemos senão o que exigem os condicionamentos da documentação, das línguas, da bibliografia" (VEYNE, 1989, p. 32).

O que está por trás de suas contribuições é a idéia de relativização da noção de fato histórico e a discussão da relação que o pesquisador estabelece com seu objeto. Se o historiador traduz um determinado fenômeno (e não "deixa que os povos falem", uma idéia bastante idealizada), importa a pergunta que vai conduzir o seu olhar; e nesse sentido "olhar para o lado", "para trás" ou "para frente" podem ser, da mesma forma, úteis para seu esforço de entendimento.

Para Veyne (1989), o estabelecimento de invariantes é nada mais do que exigir uma teoria que pode proporcionar à História certos conceitos e instrumentos de explicação; é o próprio centro da prática histórica. Assim, ironiza aos que resistem à idéia:

A idéia de invariante, ou a palavra, desconcertará
um pouco. Uns dirão que não vêem o que isso traz
e que utilidade tem, não se apercebendo de que
eles próprios o usam sem saber [...]. Outros terão
temores pudicos: não seria o invariante a própria
negação da evolução histórica e uma ideologia
conservadora que afirma que a natureza humana é
imutável? Pior ainda, suspeitar-se-á de que tudo
isso é história comparada, esse monstro, que é ao
mesmo tempo e em larga escala um animal mítico.
(VEYNE, 1989, p. 14).

A provocação de Veyne (1989) caminha no sentido de apontar que, se materialmente a História se escreve com fatos, formalmente

Movimento, Porto Alegre, v. 13, n. 03, p. 11-41, setembro/dezembro de 2007. 
deve ser produzida com problemáticas e conceitos. Logo, recuperamos a idéia de interdisciplinaridade já discutida:

\begin{abstract}
Qualquer historiador é implicitamente um filósofo, pois que decide sobre o que se considera antropologicamente interessante. Tem de decidir se atribuirá importância aos selos de correio através da história, ou antes às classes sociais, às nações, aos sexos e às suas relações políticas, materiais e imaginárias. (VEYNE, 1989, p. 6).
\end{abstract}

Exemplifiquemos com nosso objeto de estudo. Se quisermos entender melhor como se deu a apreensão do esporte por parte das camadas populares, parece ser interessante compreender como isso se deu em mais de uma localidade, seja no mesmo período ou não. Esse deslocamento pode criar situações de estranhamento, chamandonos a atenção para novas dimensões que podem ter passado desapercebidas a partir de um olhar muito focado. Se de um lado nos permite entender as especificidades e singularidades, de outro também nos permite entender certas regularidades.

A história do futebol argentino é certamente anterior à do brasileiro. Na década de 1840 já se disputavam jogos informais e os primeiros clubes surgiram na década de 1860, enquanto no Brasil isso ocorreu no final do século XIX. ${ }^{12}$ É verdade que o contexto político também tem suas singularidades, sendo inclusive a República Argentina anterior a nossa. A despeito dessas diferenças (contextos políticos, localidades, datas), a comparação entre a apreensão do futebol pelas camadas populares nos dois países pode nos ajudar a entender melhor o problema, cada uma das nações e algo da própria América Latina, desde que tenhamos em conta os alertas já descritos nesse estudo. Vejamos que com isso coloca-se em questão a visão mais tradicional do binômio espaço e tempo nas pesquisas históricas, rompendo-se com a idéia de nexos causais, lineares e evolutivos.

Por isso, tornam-se possíveis esforços como os de Kimon Speciale (2007), que discute a formação do herói alemão no período

12 Para uma discussão sobre tal assunto, ver os estudos de Pereira (2000) e Fabbri (2006).

Movimento, Porto Alegre, v. 13, n. 03, p. 11-41, setembro/dezembro de 2007. 
pré-Segunda Grande Guerra, comparando com a formação do herói grego e do herói romano, fazendo uso denotado do filme Olympia (1938), de Leni Riefenstahl, como fonte privilegiada. Da mesma forma, parece interessante a investigação de Álvaro do Cabo, que compara a realização das Copas do Mundo nos países do Mercosul (Uruguai, 1930; Brasil, 1950 e Argentina, 1978) como forma de construção da imagem nacional perante o cenário mundial, bem como estratégias de estabelecimento de relações internacionais.

A questão das analogias, que traz benefícios e riscos, passa aqui a ser um exercício caro e fundamental para os historiadores que fazem uso do método comparado. Um exemplo disso pode ser encontrado em nossas experiências recentes de construção de um campo de investigação de práticas corporais na Grécia Antiga, Roma Antiga e Modernidade. ${ }^{13}$ Se adotarmos o conceito de campo esportivo de Pierre Bourdieu (1983), que nos parece bastante interessante, dificilmente podemos dizer que o que havia na Grécia e na Roma da Antigüidade tratava-se de esporte. Contudo, aqui podemos usar a categoria "esporte" como referência para traçar analogias, buscando semelhanças e diferenças, obviamente fazendo as devidas ressalvas. Com isso não estamos dizendo que o que os gregos e romanos faziam era esporte, apenas estamos fazendo dialogar diferentes contextos a partir de uma categoria que pode ser útil para ampliar nosso olhar sobre os objetos, tanto na Antigüidade quanto na contemporaneidade.

Para exemplificar um pouco mais como temos operado com o método comparado, passo a brevemente discorrer sobre nosso principal projeto em desenvolvimento, "Esporte e Arte: diálogos", ${ }^{14}$ que tem como objetivos: a) catalogar e disponibilizar em bancos de dados na internet obras de arte (cinema, artes plásticas, música, artes cênicas, literatura) que representem o esporte; b) discutir as

\footnotetext{
${ }^{13}$ Como fruto primeiro dessa experiência, estamos oferecendo (1ํㅗㄴ semestre de 2007), no Programa de Pós-Graduação em História Comparada/IFCS/UFRJ, a disciplina História Comparada da Práticas Corporais: Grécia, Roma e Antiguidade, conduzida por mim, pelo prof. Dr. Fábio Lessa e pela Profa. Normas Mendes.

${ }^{14}$ Maiores informações podem ser obtidas em: www.lazer.eefd.ufrj.br/esportearte.
}

Movimento, Porto Alegre, v. 13, n. 03, p. 11-41, setembro/dezembro de 2007. 
representações de esporte nessas obras; c) discutir os diálogos intersemióticos entre esporte e diferentes artes; d) desenvolver estratégias pedagógicas para trabalhar o esporte por meio das obras de arte. O projeto, portanto, conjuga preocupações de memória, de História, de Estudos Culturais e de Pedagogia. Faz-se necessário, assim, o uso de arcabouço teórico das Ciências Humanas e Sociais como um todo; uma perspectiva de trabalho claramente interdisciplinar.

Em seu interior, o projeto contempla várias perspectivas de comparação, além do já citado aporte de diversas áreas de conhecimento. Uma dessas é a própria análise comparada das relações entre as linguagens no contexto da modernidade e pós-modernidade. Como se estabeleceram os encontros entre esporte e as diversas manifestações artísticas no decorrer da história? Haveria maiores semelhanças entre o esporte e a arte enquanto práticas sociais tão importantes e influentes no decorrer do século XX? No contexto brasileiro, como isso terá se estabelecido? Como as obras de arte podem se constituir enquanto potenciais fontes para ampliar nosso olhar sobre a presença do fenômeno esportivo em nossa sociedade, ajudando-nos a descortinar a sua peculiaridade e sua relevância?

Vale considerar a afirmação de Bernard Jeu (1992, p. 21):

\begin{abstract}
A arte e a literatura são para o esporte uma sociologia indireta, uma psicanálise, um testemunho [...] A investigação da presença do esporte na arte nos interessa na medida em que nos esclarece sobre a identidade do esporte e sobre o papel do imaginário na constituição das relações esportivas [...] O esporte não é simplesmente o indício de uma sociedade lúdica (ignorada ou tolerada), mas a sociedade lúdica percebida e descrita pelos meios da arte, em um quadro de expressão de sua valorização pela sociedade global.
\end{abstract}

No interior do projeto, procuramos também trabalhar com a idéia de invariante de Veyne (1989) no desenvolvimento de estudos específicos. Por exemplo: utilizando filmes internacionais e nacionais que têm o boxe como temática central como fontes privilegiadas

Movimento, Porto Alegre, v. 13, n. 03, p. 11-41, setembro/dezembro de 2007. 
para discutir a questão da construção da masculinidade ${ }^{15}$ fazendo uso de obras de arte nacionais e internacionais para discutir a presença do esporte no cenário urbano $;{ }^{16}$ tecendo uma análise comparada de diferentes filmes brasileiros para discutir a construção da idéia de identidade nacional, ${ }^{17}$ e mais recentemente desenvolvendo uma comparação entre a presença do esporte no cinema da América do Sul, com ênfase no cinema brasileiro e argentino. ${ }^{18}$

Enfim, o que tentamos argumentar é que a História Comparada pode conceder boas contribuições para que não só extrapolemos a nossa visão sobre os arranjos locais do fenômeno esportivo (a partir de problemas centrais que serão elencados pelo historiador), como mesmo permite que redimensionemos essa visão inicial, já que na comparação possivelmente surgirão problemas antes não visualizados. A questão não é, portanto, abandonar o local, mas, passando do local ao global, tanto compreender o objeto para além de suas peculiaridades, como mesmo reforçar ou negar nosso entendimento primeiro sobre essas especificidades.

\section{CONCLUSÃO}

Efetivamente, nos últimos anos, avançamos muito no que se refere à realização de estudos históricos que têm como objeto de estudo as práticas corporais. Compreendemos melhor do que antes nossos problemas? Certamente que sim, mas o que tentamos argumentar é que é possível que o método comparativo possa contribuir para ampliar ainda mais nosso entendimento acerca de nossos objetos de investigação e das problemáticas construídas ao seu redor.

\footnotetext{
${ }^{15}$ Ver estudo: MELO, V. A. ; VAZ, Alexandre Fernandez . Cinema, corpo, boxe: suas relações e a construção da masculidade. ArtCultura, Uberlândia, v. 8, p. 139-160, 2006.

${ }^{16}$ Cito o estudo: MELO, V. A.; PERES, F. F. Lazer, esporte e cultura urbana na transição dos século XIX e XX: conexões entre Paris e Rio de Janeiro. Logos, Rio de Janeiro, v. 12, n. 22, p. 75-92, 2005.

${ }_{17}$ Refiro-me ao estudo: MELO, Victor Andrade de. Eficiência x jogo de cintura: Garrincha, Pelé, Nélson Rodrigues e a construção da identidade nacional. In: CONGRESSO BRASILEIRO DE CIÊNCIAS DO ESPORTE, 14, 2005. Anais... Porto Alegre: UFRGS, 2005.

${ }^{18}$ MELO, Victor Andrade de. A presença do esporte no cinema da América do Sul: um projeto de pesquisa. Rio de Janeiro: 2007. (mimeo).
}

Movimento, Porto Alegre, v. 13, n. 03, p. 11-41, setembro/dezembro de 2007. 
Mesmo na Europa e nos Estados Unidos, onde o "movimento" da História do Esporte já está mais estruturado, ainda não é comum a realização de estudos comparados. Acerca disso, comenta criticamente Booth (2000, p. 5):

Poucos acadêmicos consideram a inovação metodológica como uma característica da História do Esporte. Ao contrário, não só a maioria dos historiadores é tímida em temas filosóficos e práticos que envolvem metodologia, como aqueles que discutem seu método o fazem em apêndices ou notas de rodapé.

Na verdade, Hannick (2001) nos mostra que na História como um todo, ainda que espaços importantes tenham sido conquistados, persistem reticências quanto às contribuições do método, algo que tem profunda relação com o próprio desenvolvimento da disciplina.

Obviamente não é nosso intuito apresentar a História Comparada como um remédio para todos os males. Sobre isso, diretamente relacionado à História do Esporte, nos fala Booth (2000, p. 17):

Comparação sistemática, isso deve ser enfatizado,
não é suficiente para estabelecer relações causais
em todos os casos históricos. Obviamente há muitas
oportunidades onde o historiador simplesmente
deseja reconstruir a estrutura causal de um caso
particular sem paralelo com outro caso geral.

Apenas argumentamos que suas propostas, suas potencialidades e possibilidades, a despeito dos limites aqui apresentados, oferecem oportunidades concretas de permitir a busca de sínteses históricas mais profundas, algo de que ainda carece nossa produção historiográfica atual. O método comparativo pode ainda nos abrir oportunidades de passarmos de nossos importantes estudos locais para apreensões mais amplas, abrindo diálogo do local e do nacional com o global.

Os exemplos de nossas investigações aqui apresentadas, que se tratam de estudos em desenvolvimento, deixam ainda muitas questões ainda a serem respondidas. O que desejamos destacar nesse momento é a iniciativa de construção de uma proposta coerente e

Movimento, Porto Alegre, v. 13, n. 03, p. 11-41, setembro/dezembro de 2007. 
articulada de realização de estudos históricos de natureza comparada. Por ora, podemos dizer que as perspectivas parecem alvissareiras.

Enfim:

Estudos partindo de uma problemática comum podem analisar estruturas, processos e mentalidades em duas ou mais sociedades, seja para acentuar diferenças, seja para encontrar analogias, de qualquer maneira, para ampliar a base documentária, propor uma interpretação das evoluções baseada no conhecimento de realidades sociais, econômicas e políticas diferentes. (HAUPT, 1998, p. 211).

Obviamente esse esforço de comparação deve ser eivado de cuidados, notadamente quando falamos de países distintos. Como bem chama a atenção Kocka (2003, p. 44):

O novo interesse em cruzamentos transnacionais é mais bem-vindo e promissor. Entretanto, não se deve afastar, mas sim se deve incorporar uma comparação rigorosa, que permanece particularmente indispensável para estudos históricos com alcance global, se eles não quiserem se tornar meramente especulativos ou folhetinescos. ${ }^{19}$

No caso da América Latina, isso parece ainda mais urgente e fundamental, inclusive pelo fato de que o desenvolvimento dos estudos históricos ligados às práticas corporais institucionalizadas é significativamente menos estruturado do que no continente europeu e do que nos Estados Unidos, como demonstra Joseph Arbena (1999). Observe-se que não estamos falando de qualidade, no que estamos pari passu com a produção mundial, mas de organização em entidades, publicação de periódicos, sistematização do campo.

Gostaria de insistir um pouco mais nesse debate por ver também aqui uma necessidade de fortalecer nossa posição no cenário internacional da "História do Esporte". Renato Ortiz vai direto ao ponto ao afirmar que grande parte das interpretações sobre nosso

\footnotetext{
${ }^{19}$ Um fértil debate sobre os desafio de construção de uma história transnacional pode ser observado no estudo de Hartmut Kaeble (2005).

Movimento, Porto Alegre, v. 13, n. 03, p. 11-41, setembro/dezembro de 2007.
} 
continente é traçada por latino-americanistas profissionais, que trabalham fora da América Latina, notadamente em universidades norte-americanas (2001). Adrián Gorelick (2004), nessa esteira, nos conclama a buscar novas maneiras de escrever nossa história latinoamericana, deixando de insistir somente na reflexão sobre a influência européia e norte-americana, ampliando nossas compreensões acerca dos contatos entre nossos países, extrapolando as iniciativas de construção de histórias somente nacionais. Segundo sua sugestão, necessitaríamos buscar: "[...] objetos supra o transnacionales. Es decir, la delimitación de problemas o de zonas de historicidad cuyo pasado no es necesariamente nacional o no se agota exclusivamente en lo nacional" (GORELICK, 2004, p. 124).

Vejamos que há aqui uma dupla dimensão que devemos ter em vista: entender o comparativismo no cenário latino-americano como, em certo sentido, uma prática contra-hegemônica (ampliando a compreensão de nossa construção cultural para além das interferências de Europa e dos Estados Unidos), não deve significar o reforço das velhas estratégias homogeneizadoras: “[...] la estratégia comparativista funciona [...] como forma de interrumpir la homogeneización nacionalista - y, a partir de esta primera deconstrucción, también la homogeneización latinoamericanista que se deriva de ella" (GARRAMUÑO, 2004, p. 156).

Um maior desenvolvimento dos estudos históricos em nosso continente certamente não somente nos interessa, a nós latino-americanos, mas também a todos os pesquisadores da temática, que hoje parece pouco compreender dos nossos arranjos específicos. Concordo plenamente com as palavras de Arbena (1999, p. 27):

\begin{abstract}
Eu reenfatizo meu argumento de que a construção de uma teoria válida requer uma perspectiva universal. Não podemos seriamente falar sobre o espaço do esporte no comportamento humano ou da conexão entre esporte e imperialismo cultural ou do espaço do esporte na globalização recente, etc., sem olhar como isso, e outros padrões, tem ocorrido em diferentes contextos geográficos, temporais e culturais.
\end{abstract}

Movimento, Porto Alegre, v. 13, n. 03, p. 11-41, setembro/dezembro de 2007. 
O próprio Arbena admite, contudo, que não se podem observar esforços significativos de relacionamento mútuo e de busca de um maior diálogo, o que certamente tem relação com dificuldades lingüísticas, já que o inglês é a língua mais amplamente aceita no mundo acadêmico, e com um provável etnocentrismo, expresso na maior valorização de referências em inglês (e a comum exigência de que estejam contempladas nos estudos realizados) e mesmo da forma de narrativa e argumentação mais comumente observada na língua inglesa, substancialmente diferente da nossa forma latino-americana de escrever.

Portanto, esses esforços de diálogo e de organização dos pesquisadores e pesquisas latino-americanas na área de história das práticas corporais institucionalizadas devem ter intencionalidades claras: o maior conhecimento mútuo permitirá caminharmos mais próximos, compreender-nos de forma mais profunda, não só para que melhor possamos entender nossas sociedades, mas inclusive para contrapor os limites dos atuais modelos acadêmicos internacionais, ao apresentarmos com competência as peculiaridades que tornam os nossos acontecimentos insubstituíveis se existe o desejo de uma compreensão mais global acerca de nossos objetos, em suas interrelações com a sociedade.

Movimento, Porto Alegre, v. 13, n. 03, p. 11-41, setembro/dezembro de 2007. 
For a comparative history of sports: possibilities, potentialities and limits

Abstract: For many years, the Brazilian historiographic production about corporal practices, including sports, was limited to a few references. However since the 1990's it is possible to observe a growth of the number of historical studies of this nature. A characteristic of this production is that normally they are about local or regional realities. The aim of this article is to discuss the possibilities, potentialities and limits of the method of Comparative History to extend the contributions of sport historical studies. We hope it may contribute to problematize the current stage of our historiographic production, presenting landmarks in order to continue the process of qualification of our inquiries, and even to establish more usual contacts to the international scientific community.

Keywords: Sports. History. Historiography.

Por una historia comparada del deporte: posibilidades, potencialidades y limites.

Resumen: Durante muchos años, la producción historiografica brasileña ligada a las prácticas corporales institucionalizadas, incluso el deporte, estuve limitada a pocas referencias. Sin embargo desde la década de 1990 es posible observar un crecimiento del número de estudios históricos de esta naturaleza. Una característica de esta producción es que normalmente tratanse de estudios locales o regionales. Esto artículo tiene por objetivo reflejar sobre las posibilidades, potencialidades y límites del método de la Historia Comparada para los estudios históricos del deporte. Esperamos que pueda contribuir para problematizar el actual nivel de nuestra producción historiografica, presentando alternativas para dar continuidad al proceso de calificación de nuestras investigaciones, y mismo ampliar nuestro dialogo com la comunidad científica internacional.

Palabras clave: Deporte. Historia. Historiografía.

Movimento, Porto Alegre, v. 13, n. 03, p. 11-41, setembro/dezembro de 2007. 


\section{REFERÊNCIAS}

ALABARCES, Pablo. Futbologías: fútbol, identidad y violencia em America Latina. Buenos Aires: CLACSO, 2003.

ARBENA, Joseph L. History of Latin American Sports: the end before the beginning? Sporting Traditions, Londres, v. 16, n. 1, p. 23-28, nov.1999.

BARROS, José D’Assunção. História Comparada: um novo modo de ver e fazer a história. Revista de História Comparada, Rio de Janeiro, v. 1, n. 1, p. 1-30, jun.2007.

BARROS, José D’Assunção. O campo da História. Petrópolis: Vozes, 2004.

BOOTH, Douglas. From allusion to causal explanation: the comparative method in sports history. International Sports Studies, Londres, v. 22, n. 2, p. 5-20, 2000.

BURKE, Peter. A Escola dos Annales. São Paulo: Unesp, 1992.

BURKE, Peter. História e teoria social. São Paulo: Unesp, 2002.

BURKE, Peter. O que é história cultural? Rio de Janeiro: Jorge Zahar, 2005.

CABO, Álvaro do. As copas do Mercosul (Uruguai, 1930, Brasil, 1950 e Argentina, 1978): uma análise comparada sob a perspectiva das relações internacionais. Projeto de Pesquisa (Mestrado em História Comparada) - Programa de Pós-Graduação em História Comparada, Instituto de Filosofia e Ciências Sociais, UFRJ, Rio de Janeiro, 2006.

CARDOSO, Ciro Flamarion; BRIGNOLI, Hector Perez. Os métodos da História. Rio de Janeiro: Graal, 1983.

DETIENNE, Marcel. Comparar o incomparável. São Paulo: Idéias e Letras, 2004.

DIAS, Cleber Augusto. Urbanidades na natureza: esporte e cidade, surfe e montanhismo - uma análise comparada (décadas de 1960 e 1970). Projeto de Pesquisa (Mestrado em História Comparada) - Programa de Pós-Graduação em História Comparada, Instituto de Filosofia e Ciências Sociais, UFRJ, Rio de Janeiro, 2006.

DRUMOND, Maurício. A nação nas quatro linhas: futebol, política e comunicação massiva no nacional-estatismo de Vargas (1930-1945) e Perón (1946-1955). Projeto de Pesquisa (Mestrado em História Comparada) - Programa de PósGraduação em História Comparada, Instituto de Filosofia e Ciências Sociais, UFRJ, Rio de Janeiro, 2006.

FABBRI, Alejandro. El nacimiento de una pasión. Buenos Aires: Capital Intelectual, 2006.

Movimento, Porto Alegre, v. 13, n. 03, p. 11-41, setembro/dezembro de 2007. 
FERREIRA, Kimon Speciale. $O$ atleta e a formação do herói alemão no período pré-Segunda Grande Guerra: uma análise comparada com o herói grego e romano a partir do diálogo com Olympia, de Leni Riefenstahl. Projeto de Pesquisa (Mestrado em História Comparada) - Programa de Pós-Graduação em História Comparada, Instituto de Filosofia e Ciências Sociais, UFRJ, Rio de Janeiro, 2006.

FOER, Franklin. Como o futebol explica o mundo. Rio de Janeiro: Jorge Zahar, 2005.

GARRAMUÑO, Florencia. Para qué comparar? Tango y samba y el fin de los estudios comparatistas y de área. Prismas: Revista de História Intelectual, Quilmes, n. 8, p. 151-162, 2004.

GIULIANOTTI, Richard (Ed.). Sport and modern social theorists. Nova York: Palgrave Macmillan, 2004.

GIULIANOTTI, Richard. Sport: a critical sociology. Cambridge: Polity Press, 2005

GORELIK, Adrian. El comparatismo como problema: una introducción. Prismas: Revista de História Intelectual, Quilmes, n. 8, p. 121-128, 2004.

HANNICK, J. M. Simples réflexions sur l'Histoire Compareé. Folia Electronica Classica, n. 2, jul./dez. 2001. Disponível em: <http://www.bcs.fltr.ucl.ac.be/fe/ 02>. Acesso em: 20 dez de 2006.

HAUPT, Heinz-Gerhard. O lento surgimento de uma história comparada. In: BOUTIER, J.; JULIA, D. (org.). Passados recompostos: campos e canteiros da História. Rio de Janeiro: UFRJ: FGV, 1998.

JEU, Bernard. Analyse du Sport. Paris: PUF, 1992.

KAELBLE, Hartmut. O debate sobre a comparação e a transferência: e agora? Tradução de Álvaro Bragança Júnior. Disponível em: <http://geschichtetransnational.clio-online.net/forum/type>. Acesso em: 10 jul. 2006.

KOCKA, Jurgen. Comparison and beyond. History and Theory, Londres, n. 42, p. 39-44, fev. 2003.

KULA, Witold. Problemas y métodos de la história econômica. Barcelona: Península, 1974.

MELO, Victor Andrade de. História da Educação Física e do Esporte no Brasil. São Paulo: Ibrasa, 1999.

ORTIZ, Renato. Estúdios culturales, fronteras y transpasos. Punto de Vista, Buenos Aires, n. 71, dez. 2001.

Movimento, Porto Alegre, v. 13, n. 03, p. 11-41, setembro/dezembro de 2007. 
PEREIRA, Leornardo Affonso de Miranda. Footballmania: uma história social do futebol no Rio de Janeiro, 1902-1938. Rio de Janeiro: Nova Fronteira, 2000.

SANTOS, Ricardo Pinto dos. A apreensão do futebol pelas camadas populares no Brasil e na Argetina (1889-1919): uma análise comparada. Projeto de Pesquisa (Mestrado em História Comparada) - Programa de PósGraduação em História Comparada, Instituto de Filosofia e Ciências Sociais, UFRJ, Rio de Janeiro, 2006.

SCHETINO, André. Pedalando na modernidade: uma análise comparada da presença da bicicleta e do ciclismo no Rio de Janeiro e Paris na transição dos séculos XIX e XX. Projeto de Pesquisa (Mestrado em História Comparada) Programa de Pós-Graduação em História Comparada, Instituto de Filosofia e Ciências Sociais, UFRJ, Rio de Janeiro, 2006.

THEML, Neide; BUSTAMANTE, Regina. História Comparada: olhares plurais. Estudos Iberamericanos, Porto Alegre, v. 29, n. 2, p. 7-22, 2003.

VEYNE, Paul. O inventário das diferenças. Lisboa: Gradiva, 1989.

WEBER, Eugene. França fin-de-siecle. São Paulo: Companhia das Letras, 1988.

Movimento, Porto Alegre, v. 13, n. 03, p. 11-41, setembro/dezembro de 2007. 